FINAL DRAFT accepted in December 2021 for publication in the journal Action Research. To cite this article please see:

Treacy, D. (2022). Appreciating situations of breakdown for researcher reflexivity. Action Research.

https://doi.org/10.1177/14767503211073083

\title{
Appreciating situations of breakdown for researcher reflexivity
}

\author{
Danielle Shannon Treacy
}

\begin{abstract}
Responding to the identified need for reflection, critique and evaluations of appreciative inquiry (AI), a form of action research, this article presents a critical reflection on an application of AI in a cross-cultural music education research project. AI was selected as it appeared to both have potential for addressing the complexities related to power imbalances, ethnocentrism, and coloniality inherent in a project aiming to co-develop music teacher education in Finland and Nepal, and because its 4D model supported the co-constructing of visions, which was central to the project. The critical reflection presented in this article focussed on three situations of breakdown that occurred during the research process. Analysis of these breakdowns highlighted the need for researchers to engage responsibly in research as participants, account for dreaming as an unevenly distributed capacity when working with visions or aspirations, and develop skills facilitating collaborative spaces that cultivate listening for and appreciating difference. The article concludes by recognising the limitations of undertaking this reflection independently rather than collaboratively and by cautioning against the instrumentalization of appreciation, calling instead for sincere appreciation. Overall, the article contends that the process of identifying and generating new understandings of breakdowns is a powerful approach for stimulating researcher reflexivity.
\end{abstract}

Keywords: appreciative inquiry, cross-cultural research, music education research, research ethics, reflexivity 


\section{Introduction}

This article began as a critical reflection on an application of Appreciative Inquiry (e.g., Cooperrider et al., 2005; Watkins et al., 2011; henceforth AI), a form of action research, and its potentials for ethically engaging in cross-cultural research (Liamputtong, 2010). It therefore responds to the identified need for reflection, critique, and evaluations of AI (e.g., Grant \& Humphries, 2006; Messerschmidt, 2008; van der Haar \& Hosking, 2004) and the criticisms that AI literature is "very often evangelical about its own advantages" (Dick, 2004, p. 427). While AI evaluation efforts often focus on its outputs (Grant \& Humphries, 2006), this article focuses on the process, and, more specifically, the "breakdown[s] in understanding" (Brinkmann, 2014, p. 722) that stimulated researcher reflection following the project's completion. Through this reflection, the article extends beyond its initial aim and responds to the call for action researchers "to contribute to conversations-for-change about ways of knowing, doing and being” (Bradbury et al., 2019, p. 9, emphasis original), posing the question: How might generating new understandings of breakdowns support practitioners in ethically engaging in cross-cultural research?

Drawing upon work by van der Haar and Hosking (2004), I employ storytelling as the means to critically reflect on the research process. Following a brief outline of the research context and the rationale for including AI in the methodology, I recount three situations of breakdown that caused me "to stop and wonder" when "Something seem[ed] strange, confusing, and maybe even worrying” (Brinkman, 2014, p. 723). These stories are presented with the understanding that narrative inquiry has the power to inform, since "The moment of disquiet, the instance of unsettling, and the recognition of certainties troubled may be the very times and spaces where insight takes root” (Barrett \& Stauffer, 2009, p. 2). Brinkmann (2014) contends that when something makes qualitative researchers stumble, they should allow themselves "to stay unbalanced for a moment longer than what is comfortable, for this is 
where [they] may learn something new" (p. 724). The three situations of breakdown are therefore intentionally separated from their analyses and the ethical possibilities they suggest for cross-cultural research practice, not only to "give readers greater space to form their own judgments" (van der Haar \& Hosking, 2004, p. 1032), but to represent the time I required for sense-making in my own journey as a practitioner. The article therefore attends to the two interwoven tasks of a critical scholar suggested by Aaron Kuntz (2015): to understand the means by which the breakdowns arose and to imagine possibilities that extend from these new understandings.

\section{The cross-cultural context framing the methodological choices}

The context of this critical reflection is a research project that arose following the adoption of music as a new subject in the Nepali National Curriculum for lower and upper secondary school students (ages 12-18). With no formal government-recognized program of music teacher education in the country, representatives of the Nepal Music Center initiated collaboration with the Sibelius Academy of the University of the Arts Helsinki. The resulting collaboration aspired to avoid simply exporting Finland's model of music teacher education to Nepal and other such unidirectional development. Instead, the aim was to co-develop context-specific music teacher education in both institutions. As part of this collaboration, a research project involving several sub-projects emerged ${ }^{1}$. The sub-project discussed in this article (Treacy, 2020) was conceived as a way of engaging musician-teachers working in the Kathmandu Valley in the co-development process. Recognising both the significance of teachers' visions in their lives and work (e.g Hammerness, 2004; 2006) and the task of

\footnotetext{
${ }^{1}$ Global Visions Through Mobilizing Networks: Co-Developing Intercultural Music Teacher Education in Finland, Israel and Nepal (See https://sites.uniarts.fi/web/globalvisions)
} 
contemporary music teacher education to equip professionals with the capacity to engage with an uncertain future, the sub-project focussed on musician-teachers' visions of music education in Nepal. Rather than exploring the visions of individuals, however, the importance of unified and shared visions in both teacher education and music teacher education (Klette \& Hammerness, 2016; Orzolek, 2015) inspired the co-constructing of visions of music education in Nepal together in groups of musician-teachers.

The sub-project took place from August 2014 to February 2020. In designing the methodology, I adopted an anti-colonial stance (Patel, 2014) and, taking guidance from Liamputtong (2010), aspired to engage in collaborative research at all stages. Stage One of the project focussed on developing understandings of what was for me an unfamiliar cultural context. During two three-week visits to the Kathmandu Valley in 2014 I visited schools and interviewed school administrators and musician-teachers guided by collaborative (Lassiter, 2005) and educational (Pole \& Morrison, 2003) ethnography. During this stage I worked with the Nepal Music Center and a Nepali employee of this institution hired to work as a research assistant. Our collaboration supported initiating and building relationships, negotiating language issues, and learning to conduct the research in a culturally respectful and appropriate manner. These first visits laid the groundwork for Stage Two which moved beyond listening to practitioners individually and instead facilitating spaces for musicianteachers to meet and discuss as a community of experts. As the focus of Stage Two was coconstructing visions with musician-teachers, I sought an approach for doing so that aligned with the heightened ethical and moral responsibility required in cross-cultural research (Liamputtong, 2010). AI appeared to meet these needs. 


\section{The turn to appreciative inquiry}

AI is a widely used approach to organizational development first introduced as "a conceptual reconfiguration of action research" (Cooperrider \& Srivastva, 1987/2013, p. 10). In response to the dominant logical positivist frame of the late 1980s, Cooperrider and Srivastva (1987/2013) proposed this reconfiguration based on two points of contention. First, they argued that the focus on action in action research, instead of the development of theoretical knowledge, damaged the potential of action research for social innovation. Second, they argued that the problem-solving approach to action research was conservative and tied research to the "already known," thus constraining the imagination and the potential for generating new knowledge and theory (p. 46). Cooperrider and Srivastva (1987/2013) thus offered AI as "a research perspective" (p. 53) with four principles: It should 1) begin with appreciation for the current state of what is, 2) generate applicable theoretical knowledge, 3) provoke realistic developmental opportunities of what might be, and 4) be collaborative (pp. 54-55). In the three decades since this first article, AI and its guiding principles have developed and evolved with the most influential and widely accepted (Bushe, 2012) principles now being those identified by Cooperrider and Whitney in 2001:

1. The Constructionist Principle, meaning that $\mathrm{AI}$ is theoretically grounded in social constructionism;

2. The Principle of Simultaneity that recognizes that inquiry is intervention, thus inquiry and change are not separate but simultaneous;

3. The Poetic Principle that values the telling and hearing of stories in inquiry and change processes;

4. The Anticipatory Principle that asserts that current behaviour is guided by images, particularly positive images, of the future; and 
5. The Positive Principle which emphasises the importance of positive affect and social bonding for supporting and sustaining change.

AI aligned with my aspiration to engage in collaborative research, and I was particularly drawn to its starting point of appreciation, which appeared to have potential for addressing the complexities of power and ethnocentrism inherent in the project. I had been concerned, for example, that as a foreign researcher I could be positioned as an outside expert or evaluator (e.g., Hammersley \& Atkinson, 2007). Through emphasising an appreciation of local knowledge, traditions, and educational approaches, I hoped to instead facilitate equitable research relationships and counter "a colonial way of thinking in which the other... is defined as lacking and as 'being-in-need-of'” (Biesta, 2017, p. 89). Instead, appreciation appeared to support the privileging of voices, experiences, and expertise of the participating musician-teachers and the positioning of us as equals learning from and with each other. I thus adopted an appreciative lens already during the above mentioned ethnographic first stage of the project. Importantly, while much of the critique of AI is related to its emphasis on the positive, I interpreted appreciation as respecting and acknowledging what is meaningful for participants (Ridley-Duff \& Duncan, 2015), and honouring the full range of their lived experiences (Fitzgerald et al., 2010). At no point did I conceptualise AI as "an inquiry into 'the positive'" (Bushe, 2012, p. 94), try to maintain a focus on 'the positive', or privilege the positive.

AI took a substantial role in Stage Two, when its 4D model (e.g. Cooperrider et al., 2005) was used to guide the co-constructing of visions of music education in Nepal with musician-teachers through a series of sixteen workshops over an eleven-week period in 2016. During this stage, research collaboration intensified as I worked closely with a local musician-teacher hired to work as co-facilitator. In addition, collaboration expanded to also include a second music institute and a private school. Once this eleven-week period ended 
and I returned to Finland, collaboration was sustained through: 1) an unsearchable, membersonly Facebook group for ongoing discussion with workshop participants; 2) a dialogic researcher diary ${ }^{2}$ with the co-facilitator; and 3) co-authoring with Nepali partners, including the principal of the Nepal Music Center, the co-facilitator, a member of the research project's international advisory board, and a musician-teacher who had participated in the workshops. Co-authoring was an integral part of analysis and interpretation as the developing texts became "the centerpiece of evolving, ongoing conversation" (Lassiter, 2005, p. 7). In addition, three visits of approximately one-week each to Kathmandu took place annually, which included the presentation of (co-authored) conference papers, seminars for government officials and representatives of education institutions, and workshops for musician-teachers to discuss research results and article drafts. These visits aimed to ensure that the research would continue to contribute to the community (Liamputtong, 2010).

\section{Situations of breakdown}

This section stories three situations of breakdown that I identified as part of a critical reflection on the research process. These situations correspond to different stages of the project and relate to the consequences of appreciation; the challenges of dreaming; and unheard voices. While this approach contrasts with the collaborative ethos guiding the project and van der Haar and Hosking's (2004) advice for presenting a multiplicity of views in evaluations of AI, I take this approach with the understanding that "self-interrogation and reflection [are] key elements in decolonizing efforts" (Bradley, 2012, p. 411).

\footnotetext{
${ }^{2}$ The dialogic researcher diary was a shared online diary created by the co-facilitator and me to continue regular discussions, reflect on our developing thoughts and interpretations in dialogue, ask questions and challenge our own and each other's thinking. In it we took turns writing and responding to each other's reflections weekly for a six-month period until our attention turned to crafting our upcoming co-authored conference paper.
} 


\section{The consequences of appreciation}

As previously stated, I began to apply aspects of AI during Stage One although the primary focus of this stage was developing familiarity with what was for me a new context guided by collaborative (Lassiter, 2005) and school (Pole \& Morrison, 2003) ethnography. In particular, I emphasised an appreciative approach as I visited schools, observed music lessons, and interviewed administrators $(n=9)$, musician-teachers $(n=7)$, and one composer of schoolspecific songs. Moreover, the semi-structured interview guide (Kvale \& Brinkmann, 2009) with musician-teachers was constructed by adapting the AI generic questions (Cooperrider et al., 2005, p. 25; Watkins et al., 2011, pp. 155-156) with the addition of some positively framed questions related to specific themes of the research project. As mentioned above, I considered an emphasis on an appreciation of local knowledge, experience, and expertise to be one way of facilitating equitable research relationships and addressing my concern that my visits might be perceived as a form of external evaluation or foreign interference.

While visiting schools during the beginning of the project, I encountered the schoolspecific song practice for the first time. This practice was new to me, having grown up in Ontario, Canada, and to the Finnish principal investigator of the overarching research project. We became curious about the practice and started asking questions about it both informally during conversations on our school visits, and formally in interviews with administrators and musician-teachers. On a subsequent visit to one of the private schools, the school administrators informed us that their school song had fallen out of regular use but that they were now thinking of re-implementing its practice after we raised the topic during our previous visit. They said that they had done their own research on the song following our initial questions, and that "you appreciated it, so we realised that it's a good thing to have a school song. So maybe it should be revived.... I didn't know that it had that kind of importance" (School administrator). This surprised us, as we had thought that we had been 
clear that we were just curious about a practice that was new to us, not that we perceived school-specific songs as either 'good' or 'bad'. This unintended consequence caused us particular concern, and we wondered what we could have done differently to avoid unintentionally legitimating the practice through our work.

\section{The challenges of dreaming}

The second situation of breakdown was related to the unforeseen challenges of facilitating the Dream phase of AI's 4D model. As already mentioned, during the second stage of the research project, this model was used to facilitate a process of co-constructing visions of music education during a series of sixteen workshops, which involved 53 musician-teachers in three different groups. This model was selected specifically to address a practical challenge of the research project, co-constructing visions, since this is incorporated in the model. In brief, the 4D model has four phases: Discovery, Dream, Design, and Destiny. Cooperrider, Whitney and Stavros (2005) describe how the first phase is about Discovering what participants deem to be "the best of what is" now. The second phase is the Dream phase in which participants envision "what might be" if the best moments and experiences discovered in the previous phase were to occur more regularly. In the Design phase participants coconstruct their ideal future based on a combination of what has worked in the past and the new ideas they envision for the future. Finally, in the Destiny phase participants innovate ways to move towards this ideal (p. 7). Although I had aspired to gather a small group of musician-teachers with whom to co-design the workshops, the musician-teachers' expectations for workshops led by a 'foreign expert' who was "supposed to talk all the time.... know all the things" (Musician-teacher) left this aspiration unmet. Instead, the workshops were co-designed with the co-facilitator with whom I worked, and in dialogue with a representative from each institution, the Nepali member of the project's international 
advisory board, and some other local musician-teachers with whom I had previously developed relationships. This collaboration, combined with what I had learned about the context during Stage One, supported ongoing reflection on and adjusting of the application of the 4D model - from small details such as word choice to bigger issues related to participation and how to facilitate the different phases - while attempting to attend to the possible ethnocentrism of applying methodologies developed in the USA in Nepal (for earlier applications of AI in Nepal see e.g. Messerschmidt, 2008; Odell \& Mohr, 2008).

As we began to facilitate the Dream phase of the 4D model, I soon discovered the expectations I had formed based on literature to be limited. The literature on teachers' visions (see e.g., Hammerness, 2004) suggests that visions are something teachers have, and the AI literature suggests that images of an ideal future naturally emerge from the positive examples shared during the Discovery phase (e.g., Cooperrider et al., 2005; Cooperrider \& Whitney, 2001). Our experience in Kathmandu, however, was much more challenging and characterized by a need to approach the Dream phase from multiple angles. This led to feelings of discomfort as Cooperrider and Whitney (2001) state that a 4D cycle can occur even in a rapid and informal conversation. I thus wondered how and why we had struggled with facilitating the Dream phase and not been able to meet our original intention of engaging with the 4D model as a cycle - or perhaps more accurately as a spiral - and revisiting each of the phases during the workshop series.

\section{Unheard voices}

The third situation of breakdown occurred after I had returned to Finland following the workshops and begun reflexively interpreting (Alvesson \& Sköldberg, 2009) the coconstructed visions. During the series of workshops, the challenges that girls and women encounter while studying music or pursuing a career in music in Nepal had arisen as an 
important issue. In response, and in dialogue with some female musician-teachers, I facilitated $^{3}$ one additional workshop exclusively for women to discuss the ways they had overcome challenges related to being musicians. Despite our aim to be inclusive in the planning and facilitation of the main workshop series, and gender issues being raised as part of these discussions, and even after facilitating the separate female-only workshop, none of the resulting co-constructed visions addressed gender issues.

At first, I contemplated if this absence was due to adopting an appreciative lens. In their discussion of AI, for example, Watkins, Mohr and Kelly (2011) assert that "the questions we ask set the stage for what we "find"' (p. 73). Perhaps framing the workshop discussions with positive questions had therefore led to only positive findings. This, however, did not appear to be the case. The main workshops and the women's workshop included animated discussions about gender issues, and other forms of discrimination permeating the life and practices of musicians in Nepal, such as social hierarchy based on class and the caste system. Furthermore, the co-constructed visions themselves addressed several challenges such as the lack of resources and collaboration between music institutions, and injustices such as the social stigma associated with music and being a musician in Nepal. If the focus on appreciation had contributed to building rapport and creating an atmosphere that made talking about these challenging and sensitive issues comfortable - as has also been found elsewhere (Duncan \& Ridley-Duff, 2014) - I wondered how and why some voices remained absent, silenced, or marginalised in the workshops and resulting visions, and how we could have facilitated the workshops differently to avoid this.

\footnotetext{
${ }^{3}$ As the co-facilitator with whom I worked was male, I facilitated this workshop independently to allow for a female-only space.
} 


\section{Possibilities for research practice}

As I allowed myself to remain unbalanced and learn from these situations of breakdown, I turned to theory to consider what insights the breakdowns might generate for improving research practice. The possibilities that emerged from this process of self-interrogation were to engage responsibly as participants; to understand dreaming as a capacity; and to listen for and appreciate difference.

\section{To engage responsibly as participants}

The situation when school administrators considered reviving the school-specific song practice exemplifies the AI Principle of Simultaneity: That inquiry is intervention and thus inquiry and change are not separate but simultaneous (Cooperrider \& Whitney, 2001). Awareness of the productive power of research calls upon researchers to not only reflect on how their questions influence their findings, as suggested above by Watkins and colleagues (2011). It also calls upon them to consider what their questions and inquiry make possible. Having framed our inquiry into the school-specific song practice through appreciation and having taken inspiration for our interview questions from AI's generic questions (Cooperrider et al., 2005, p. 25; Watkins et al., 2011, pp. 155-156), our inquiry was shaped through particular subjectivities, or at the very least perceived as such. Had we instead balanced our appreciative orientation and questions with more critical questions, including also asking about the challenges or dissatisfactions administrators and musician-teachers had with the songs, the outcome may have been very different. Similarly, during the additional women's workshop despite being guided by AI we focussed on discussing ways the women had overcome challenges related to being musicians, and did not discuss, for example, ways they 
identified being a woman as an advantage, which could have potentially offered another important perspective.

The possibility that emerges from this situation for research practice, however, goes beyond merely ensuring balance between appreciative and critical perspectives, or even merging critical approaches to research with AI as some of the scholars who inspired the planning of this project have called for (e.g. Bushe, 2012; Dematteo \& Reeves, 2011; Duncan \& Ridley-Duff, 2014; Grant \& Humphries, 2006; McArthur-Blair \& Cockell, 2012; Oliver, 2005; Ridley-Duff \& Duncan, 2015). This is because only attending to balance keeps the focus on the researcher(s) and fails to also account for the agency and reflexivity of research participants. As a novice researcher, I focussed on how my position as a White researcher from a foreign and internationally esteemed university, in a context that did not yet have music education or music teacher education at the university level could position me as an expert in Nepal. I thus consciously sought not to erase local knowledge and practices to be replaced by my own (e.g. Patel, 2016; Tuck \& Yang, 2012), relying on an appreciation of local knowledge, traditions, and educational approaches to do so. The school administrators' decision thus surprised me and caused feelings of shame and embarrassment about this 'mistake' I had made, which led me to try too quickly to recover and return to my interview guide. Looking back, I see how both my appreciative interview approach - which I also used intentionally to facilitate relationship building and rapport - and my attempt at a quick recovery unintentionally facilitated, rather than countered, a logics of extraction (Kuntz, 2015) that I had sought to avoid. We therefore missed an opportunity to let this situation teach us, together generating knowledge by engaging in dialogue aimed at better understanding the administrators' choice to reinstate the school-specific song, exploring the song's desirability for their school community, their motivations, and the degree to which our researcher positions and questions may have influenced their decision. This would have 
required a turn towards the discomfort of the moment "to stay in the frustrating 'middle ground'.... [and] engage with what resists" (Biesta, 2012, p. 95). Interview dialogue such as this is supported, for example, by Brinkmann (2015) in what he calls "epistemic interviews". These interviews, he suggests,

do not commodify or instrumentalize human feeling, friendship, and empathy (Brinkmann \& Kvale, 2005) .... the interviewers do not try to suck as much private information out of the respondents as possible without themselves engaging in the conversation with all the risks that are involved in this. Interviewers become participants in, rather than spectators of, the production of social life. (p. 238)

Understanding researchers first as participants could have not only resulted in deeper understandings of the school-specific song practice. It could have also better supported my aim in this project to engage responsibly and ethically with research participants as subjects, not objects, and as equals.

\section{To understand dreaming as a capacity}

My search to understand the challenges we encountered facilitating the Dream phase of AI's 4D model were not solved through reflecting on the issue in our dialogic researcher diary and asking the workshop participants directly about this challenge did not feel appropriate at the time. When I came across social-cultural anthropologist Arjun Appadurai's notion of the capacity to aspire, our challenges seemed less surprising, and I shared his texts with the cofacilitator and co-authors with whom I worked. According to Appadurai (2006), the capacity to aspire is "the social and cultural capacity to plan, hope, desire, and achieve socially valuable goals" (p. 176). Importantly, he (2004) asserts that "like any complex cultural capacity, [it] thrives and survives on practice, repetition, exploration, conjecture, and 
refutation" (p. 69). This assertion aligns with an explanation offered by a musician-teacher in a later discussion of the challenges of envisioning. He stated that the participating musicianteachers had "never had that type of experience and their school [had] also never asked how school can be made better". Moreover, just as the Discovery phase focuses on sharing stories of success, Appadurai (2013) contends that the main fuel of the capacity to aspire "lies in credible stories (from one's own life-world) of the possibility to move forward, outward, and upward" (p. 214). As this research project was part of the beginning stages of developing music teacher education in Nepal, however, such stories may have been limited since participants did not have personal experiences of formal music teacher education in Nepal as it did not yet exist - and many had not had music programs in their primary or secondary schools.

Moving beyond the specific context of this project, Appadurai's ideas may offer important perspectives for AI practitioners more broadly. The AI literature did not prepare me to view Dreaming as a capacity. Had it done so, I would have begun the process expecting that it might be challenging and require flexibility to explore a variety of approaches if necessary. Of even more ethical concern for AI practitioners, however, is Appadurai's (2004) assertion that the capacity to aspire is an unevenly distributed navigational capacity. According to Appadurai (2004), the better off or more privileged in any society have more opportunities to practice navigating the relations and pathways between ends and means, or aspirations and outcomes - the "pathways from concrete wants to intermediate contexts to general norms and back again" (Appadurai, 2004, p. 69) - and to share their complex and diverse experiences doing so with each other. This is particularly important considering AI often emphasises whole organisation and multi stakeholder cocreation, during which "it is important to strive for equality of voice" (van der Haar \& Hosking, 2004, p. 1028). Sensitivity to the possibility of diverse experiences with and 
capacities to aspire among those involved in an AI process could therefore support AI practitioners in considering ways diverse stakeholder experiences could be equally accounted for throughout the process, and how space could be opened for nurturing and developing this capacity within the process. Although this is particularly pertinent to AI practitioners, it may be equally of relevance to researchers employing other approaches to examine or explore visions or aspirations.

\section{To listen for and appreciate difference}

Further deliberation about the absence of a co-constructed vision addressing gender issues suggested that it may have been a result of the focus on consensus-building during the 4D process. In the workshops, only shared experiences - positive or negative - were attended to by the participants while co-constructing the visions. As only nine of the fifty-three workshop participants were women, they were a minority within a predominantly male group, which was reflective of their marginalised positions as musicians in Nepal. This positioning may have led them to be perceived as what music education scholar Nasim Niknafs (2021) refers to as "itinerants (non-citizens)" (p. 16). Niknafs (2021) describes how when seen as "visitors" to a certain space "the values that [itinerants] hold may also be perceived as temporary and devoid of any moral human obligation" (p. 16). Thus, she continues, "If their values are seen as impermanent, then there is no consequence for ignoring difference and reinforcing the same values that have already been institutionally established" (p. 16). In this way, AI, with its starting point of appreciating "the best of what is" (Cooperrider et al., 2005, p. 5), risks sustaining and legitimising inequitable norms, values, and beliefs. Aspirations are, according to Appadurai (2004), culturally embedded, and teachers' visions have been found to potentially be culturally biased, exclusionary, perpetuate stereotypes or suppress alternative possibilities (Hammerness, 2006). As highlighted during the workshops, cultural norms, 
ideas, and beliefs contribute to the challenges women encounter when pursuing music as a hobby or career in Nepal and thus, if seen as itinerants, any gender issues they may have raised in the workshops may have remained unheard at best, dismissed and disregarded at worst. This may have also been the case for other minorities - from different musical genres, caste/ethnic groups, and age groups. A greater awareness is therefore needed of the power imbalances permeating the consensus-reaching process (Kapoor, 2004), especially considering the aims in the 4D model of together envisioning what might be and coconstructing an ideal future.

The possibility that emerges from this situation for research practice is to find ways of moving away from the need for consensus. In the context of AI, it has already been recognised that "Consensus is not necessary for joint action" (van der Haar and Hosking, 2004, p. 1028), and evidence of this can also be seen following this research project, when a group of female musician-teachers organized an all-female concert to raise awareness and enhance female participation in music in Nepal several months after the workshops ended. However, if "oppression happens partly through not hearing certain kinds of expressions from certain kinds of people" (Bickford, 1996, p. 5, cited in Kallio, 2021, p. 171), it is the responsibility of the researcher to aspire to nurture a workshop environment where offers of different perspectives, along with the potential bravery required for voicing them, are welcomed with appreciation and curiosity aimed at better understanding each other. In such spaces "there is the possibility for dissensus to be expressed or different alternatives to be put forward" (Mouffe interviewed in Carpentier \& Cammaerts, 2006, p. 974), and critical group reflection on questions such as "who is heard, and to what end?" (Burgess, 2006, p. 203, in Kallio, 2021, p. 169) supports the group in identifying possible absences, silences and causes, to together find ways to make space for hearing more diverse perspectives. While Grant and Humphries (2006) note that dissensus is among approaches used by critical theorists, they 
contend it "appear[s to be] in direct contrast to the approaches promoted by traditional appreciative inquiry scholarship" (p. 408). van der Haar and Hosking (2004), however, emphasize that while encounters with difference may lead to ignorance, apartheid and dominance, they may equally include "dialogues - listening to other(s) - attempting to keep space open for 'different but equal' rather than different and irrelevant, wrong, evil” (p. 1023). Similarly, Niknafs (2021) asserts that "conversation and intimate listening can generate and sustain a wholesome ecosystem that can afford every member within the society - and not of the society - equitable ground from which to experiment, learn, and thrive without any precondition of citizenship, recognition, or presentation" (p. 22). This is hard work, however, as offering and listening to diverse perspectives inevitably leads to encounters with resistance. It is therefore important for AI practitioners, and anyone facilitating similar group research processes, to develop the skills required to support participants in "endur[ing] the difficulty and frustration" of staying in the middle ground (Biesta, 2012, p. 98). Skilfully facilitating wholesome ecosystems in which difference is appreciated will require sufficient space and time, and sensitivity to the needs of the group and community building within it.

\section{Conclusions}

This article has critically reflected on a research process that intentionally made use of AI in efforts to engage ethically in cross-cultural research. A major limitation of the critical reflection presented in this article has been that its process was not collaborative, despite collaboration being a central principle of $\mathrm{AI}$ and to conducting ethical cross-cultural research projects (Liamputtong, 2010). Despite my aspirations throughout the project to engage in collaborative research as an ethical stance, not all my aspirations were fulfilled. In addition to the challenges of planning the workshops with local musician-teachers mentioned above, 
engaging in collaborative research and co-authoring were influenced by differences in time commitments - as I was the only one employed full-time in this project while those with whom I worked had other concurrent responsibilities from their jobs, studies, or research projects - and differences in our experiences with research and academic writing. Thus, although we strove for regular communication and honest and open dialogue, I cannot be sure of the extent to which those with whom I worked felt free to suggest alternate interpretations or point out misunderstandings, or to which the collaboratively written texts that did emerge from this project "help[ed] resolve the problems of class and privilege" (Lassiter, 2005, p. 7). The individual approach taken in this article reflects its emergence long after the project concluded and in response to requests from scholars to learn more about a research approach rarely used in music education. A collaborative reflection, however, could have better supported the ethical aspirations of the project and led to the identification of different breakdowns and interpretations. It would therefore be fruitful for future projects to plan to incorporate ongoing and emergent evaluations - including the identification of and reflection on breakdowns - as part of the AI process, so that the evaluation is "jointly constructed by participants, who listen to (rather than talk for) others" (van der Haar \& Hosking, 2004, p. 1032).

While AI offered me support as I strove to ethically engage in cross-cultural research, the process of critical reflection culminating in this article has highlighted not only the possibilities of appreciation, but also its risks. In this project, appreciation supported community building and the valuing and privileging of local knowledge and expertise. In our efforts to learn from and with each other we therefore began by seeking "the beautiful in the Other" (Davis, 2015, p. 58). However, beyond the potential unintended consequences of appreciation, such as those discussed above, there are also risks that appreciation would be instrumentalised in research. By this I mean that appreciation may be used only as a tool for 
building relationships and rapport to extract more personal, and possibly even painful stories, from those involved in the research. To prevent appreciation from becoming manipulative, therefore, I emphasise the need for sincere appreciation. Sincere appreciation is more than an ethical stance, but a relational way of being that involves openness to learn from experience and through a high degree of reflexivity. Such reflexivity is fundamental if researchers are to avoid legitimating and sustaining the current state of what is and instead contribute to imagining and enabling new practices and possibilities towards a more ethical and socially just future.

The process of identifying and generating new understandings of the "breakdown[s] in understanding" (Brinkmann, 2014, p. 722) has proven to be a powerful approach to critical reflection. In some ways, the process culminating in this article can be likened to appreciative inquiry. Rather than beginning with a discovery of the "best of what [was]" (Cooperrider et al., 2005, p. 7, emphasis added), however, it began with moving beyond seeing the breakdowns only as mistakes or failures and instead learning to appreciate them, guided by the belief in the powerful generative potential of reflecting on them (e.g. Barrett \& Stauffer, 2009; Brinkman, 2014). Moreover, the storying of these breakdowns (Barrett \& Stauffer, 2009; Brinkmann, 2014) aligned with AI's Poetic Principle (Cooperrider \& Whitney, 200), while my turn to theory to examine them provoked developmental opportunities (Cooperrider and Srivastva, 1987/2013) through a rethinking of research practice and proposing of new possibilities. This has been a long process, for which I have found support in the words of educational research scholar Leigh Patel, and in particular her assertion that one of the most explicit decolonial moves we can make... is to sit still long enough to see clearly what we need to reach beyond. This stillness should not be confused with doing nothing. (2016, p. 88) 
Indeed, this stillness allowed me to uncover some of my unrecognized assumptions and make way for new ideas for research practice to emerge, through an "intimate engagement and selfawareness" that "chang[ed] [my]self and [my] mental models" (Bradbury et al., 2019, p. 8). As a result of this reflective process, I therefore bring to future research projects both new understandings of how to engage responsibly in research as a participant and of the need to account for dreaming as an unevenly distributed capacity when working with visions or aspirations, as well as a strong desire to develop skills in facilitating collaborative spaces that cultivate listening for and appreciating difference. These learnings extend beyond influencing my future actions as a researcher, and shape my very ways of being, not only as a researcher or teacher, but as a whole person in relation with the world. It is my hope that sharing this critical reflection might also contribute to the ways of knowing, doing and being of other researchers.

\section{Acknowledgements}

The author would like to thank Professor Eva Saether who first recommended appreciative inquiry for this project. This article has taken shape through two presentations that took place during the fall of 2020 and the author would like to thank Professor Eva Saether, and Professor David G. Hebert and Associate Professor Camilla Kvaal for the invitations to reflect critically and deeply on work that already felt 'unfinished'. Finally, the author is grateful to all those who participated in the research project, dhanyabaad!

\section{Funding}

This research was supported by the project Global Visions through Mobilizing Networks: Codeveloping Intercultural Music Teacher Education in Nepal, Finland, and Israel funded by 
the Academy of Finland (2015-2020, project no. 286162, see

https://sites.uniarts.fi/web/globalvisions) and the project Music Education, Professionalism and EcoPolitics funded by the Academy of Finland (2021-2025, project no. 338952, see https://www.uniarts.fi/en/projects/music-education-professionalism-and-eco-politics).

\section{References}

Alvesson, M., \& Skoldberg, K. (2009). Reflexive methodology: New vistas for qualitative research (2nd ed.). SAGE.

Appadurai, A. (2004). The capacity to aspire: Culture and the terms of recognition. In V. Rao \& M. Walton (Eds), Culture and public action (pp. 59-84). Stanford University Press. Appadurai, A. (2006). The right to research. Globalisation, Societies and Education, 4(2), 167-177. doi: 10.1080/14767720600750696.

Appadurai, A. (2013). The future as cultural fact: Essays on the global condition. Verso.

Barrett, M. S., \& Stauffer, S. L. (2009). Introduction. In M. S. Barrett \& S. L. Stauffer (Eds.), Narrative inquiry in music education: Troubling certainty (pp. 1-4). Springer.

Biesta, G. J. J. (2012). The educational significance of the experience of resistance: Schooling and the dialogue between child and world. Other Education: The Journal of Educational Alternatives, 1(1), 92-103.

Biesta, G. J. J. (2017). The rediscovery of teaching. Routledge.

Bradbury, H., Waddell, S., O’ Brien, K., Apgar, M., Teehankee, B., \& Fazey, I. (2019). A call to Action Research for Transformations: The times demand it. Action Research, 17(1), 3-10.

Bradley, D. (2012) Good for what, good for whom? Decolonizing music education philosophies. In W. D. Bowman \& A. L. Frega (Eds.), Oxford handbook of philosophy in music education (pp. 409-433). Oxford: Oxford University Press. 
Brinkmann, S. (2014). Doing without data. Qualitative Inquiry, 20(6), 720-725. https://doi.org/10.1177/1077800414530254

Brinkmann, S. (2015). Interviewing and the production of the conversational self. In N. K. Denzin \& M. D. Giardina (Eds.), Qualitative inquiry - past, present, and future: A critical reader (pp. 223-241). Routledge.

Bushe, G. (2012). Appreciative inquiry: Theory and critique. In D. Boje, B. Burnes, \& J. Hassard (Eds.), The Routledge companion to organizational change (1st ed., pp. 87103). Routledge.

Carpentier, N., \& Cammaerts, B. (2006). Hegemony, democracy, agonism and journalism: An interview with Chantal Mouffe. Journalism Studies, 7(6), 964-975. doi: $10.1080 / 14616700600980728$

Cooperrider, D. L., \& Srivastva, S. (2013). Appreciative inquiry in organizational life. In D. L. Cooperrider, D. P. Zandee, L. N. Godwin, M. Avital, \& B. Boland (Eds.), Organizational generativity: The appreciative inquiry summit and a scholarship of transformation (pp. 9-67). Emerald. (Original work published 1987).

Cooperrider, D. L., \& Whitney, D. (2001). A positive revolution in change: Appreciative inquiry. Public Administration and Public Policy, 87, 611-630.

Cooperrider, D. L., Whitney, D., \& Stavros, J. M. ( 2005). Appreciative inquiry handbook: For leaders of change (2nd ed.). Crown Custom Pub.

Davis, D. R. (2015). Three principles for an Asian humanities: Care first . . . Learn from . . . Connect histories. The Journal of Asian Studies, 74, 43-67. https://doi.org/10.1017/s0021911814001673.

Dematteo, D., \& Reeves, S. (2011). A critical examination of the role of appreciative inquiry within an interprofessional education initiative. Journal of Interprofessional Care, 25, 203-208. doi: 10.3109/13561820.2010.504312 
Dick, B. (2004). Action research literature: Themes and trends. Action Research, 2(4), 425444. https://doi.org/10.1177/1476750304047985

Duncan, G., \& Ridley-Duff, R. (2014). Appreciative inquiry as a method of transforming identity and power in Pakistani women. Action Research, 12(2), 117-135. doi: $\underline{10.1177 / 1476750314524005}$

Fitzgerald, S. P., Oliver, C., \& Hoxsey, J. C. (2010). Appreciative inquiry as shadow process. Journal of Management Inquiry, 19(3), 220-233.

Grant, S., \& Humphries, M. (2006). Critical evaluation of appreciative inquiry: Bridging and apparent paradox. Action Research, 4(4), 401-418. doi: 10.1177/1476750306070103

Hammerness, K. (2004). Teaching with vision: How one teacher negotiates the tension between high ideals and standardized testing. Teacher Education Quarterly, 31(4), 3343.

Hammerness, K. (2006). Seeing through teachers' eyes: Professional ideals and classroom practices. Teachers College Press.

Hammersley, M. \& Atkinson, P. (2007). Ethnography: Principles in practice (3rd ed.). Routledge.

Kallio, A. A. (2021). Towards solidarity through conflict: Listening for the morally irreconcilable in music education. In A. A. Kallio (Ed) Difference and division in music education (pp. 163-176). Routledge.

Kapoor, I. (2004). Hyper-self-reflexive development? Spivak on representing the Third World 'Other'. Third World Quarterly, 25(4), 627-647. doi:10.1080/014365904 10001678898

Klette, K., \& Hammerness, K. (2016). Conceptual framework for analyzing qualities in teacher education: Looking at features of teacher education from an international perspective. Acta Didactica Norge, 10(2), 26-52. 
Kuntz, A. M. (2015). The responsible methodologist: Inquiry, truth-telling, and social justice. Routledge.

Kvale, S., \& Brinkmann, S. (2009). InterViews: Learning the craft of qualitative research interviewing (2nd ed.). Sage.

Lassiter, L. E. (2005). The Chicago guide to collaborative ethnography. The University of Chicago Press.

Liamputtong, P. (2010). Performing qualitative cross-cultural research. Cambridge University Press.

McArthur-Blair, J., \& Cockell, J. (2012b). Inclusive spaces: Using appreciative processes to transform social structures. International Journal of Appreciative Inquiry, 14(3), 4-8.

Messerschmidt, D. (2008). Evaluating appreciative inquiry as an organizational transformation tool: An assessment from Nepal. Human Organization 67(4):454-468. doi:10.17730/humo.67.4.xp341p168m141641.

Niknafs, N. (2021). Ingratitude and the politics of obligation: The problem of (un)mutual recognition in music education. In A. A. Kallio (Ed) Difference and division in music education (pp. 11-25). Routledge.

Odell, M. J., \& Mohr, B. J. (2008). The power of a positive lens in peace building and development. In M. Avital, R. J. Boland, \& D. L. Cooperrider (Eds) Designing information and organizations with a positive lens (pp. 307-327). JAI Press.

Oliver, C. (2005). Critical appreciative inquiry as intervention in organisational discourse. In E. Peck (Ed.), Organisational development in healthcare: Approaches, innovations, achievements (pp. 205-218). Radcliffe.

Orzolek, D. C. (2015). Creating vision for music teacher education. In S. W. Conkling (Ed.), Envisioning music teacher education (pp. ix-xiv). Rowman \& Littlefield Education. 
Patel, L. (2014). Countering coloniality in educational research: From ownership to answerability. Educational Studies, 50(4), 357-377.

Patel, L. (2016). Decolonizing educational research: From ownership to answerability. Routledge.

Pole, C., \& Morrison, M. (2003). Ethnography for education. Open University Press.

Ridley-Duff, R. J., \& Duncan , G. (2015). What is critical appreciation? Insights from studying the critical turn in an appreciative inquiry. Human Relations, 68(10), 1579-99.

Treacy, D. S. (2020). Imagining possibilities: Musician-teachers co-constructing visions in the Kathmandu Valley. Sibelius Academy of the University of the Arts Helsinki. Studia Musica 80. http://urn.fi/URN:NBN:fi-fe202002145503

Tuck, E., \& Yang, K. W. (2012). Decolonization is not a metaphor. Decolonization: Indigeneity, education \& society, 1(1), 1-40.

van der Haar, D. \& Hosking, D. (2004). Evaluating appreciative inquiry: A relational constructionist perspective. Human Relations 57(8): 1017-1036.

Watkins, J. M., Mohr, B., \& Kelly, R. (2011). Appreciative inquiry: Change at the speed of imagination (2nd ed.). Pfeiffer/Wiley. 